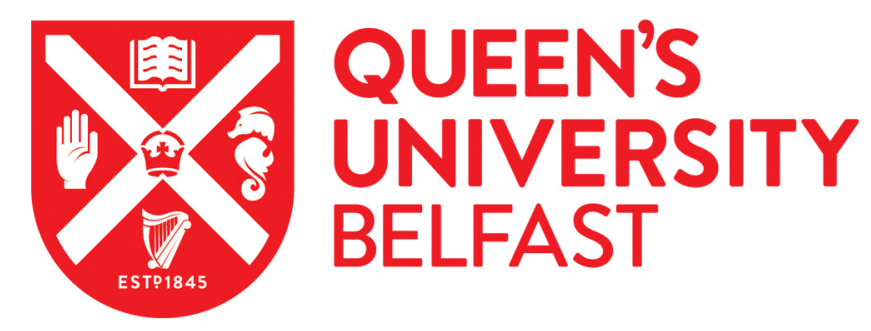

\title{
Group Design-Build-Test Projects as the Core of an Integrated Curriculum in Product Design and Development
}

Hermon, P., McCartan, C., \& Cunningham, G. (2010). Group Design-Build-Test Projects as the Core of an Integrated Curriculum in Product Design and Development. 1-9. Paper presented at EE2010, Birmingham, England, United Kingdom.

\section{Document Version:}

Publisher's PDF, also known as Version of record

\section{Queen's University Belfast - Research Portal:}

Link to publication record in Queen's University Belfast Research Portal

Publisher rights

Copyright 2010 the Authors.

\section{General rights}

Copyright for the publications made accessible via the Queen's University Belfast Research Portal is retained by the author(s) and / or other copyright owners and it is a condition of accessing these publications that users recognise and abide by the legal requirements associated with these rights.

Take down policy

The Research Portal is Queen's institutional repository that provides access to Queen's research output. Every effort has been made to ensure that content in the Research Portal does not infringe any person's rights, or applicable UK laws. If you discover content in the Research Portal that you believe breaches copyright or violates any law, please contact openaccess@qub.ac.uk. 


\title{
Group Design-Build-Test Projects as the Core of an Integrated Curriculum in Product Design and Development
}

\author{
J Paul Hermon (p.hermon@qub.ac.uk), Charles D McCartan (c.mccartan@qub.ac.uk), \\ Geoffrey Cunningham (g.cunningham@qub.ac.uk)
}

Queen's University Belfast, UK

The School of Mechanical and Aerospace Engineering at Queen's University Belfast introduced a new degree programme in Product Design and Development (PDD) in 2004. As well as setting out to meet all UK-SPEC requirements, the entirely new curriculum was developed in line with the syllabus and standards defined by the CDIO Initiative, an international collaboration of universities aiming to improve the education of engineering students. The CDIO ethos is that students are taught in the context of conceiving, designing, implementing and operating a product or system. Fundamental to this is an integrated curriculum with multiple Design-Build-Test (DBT) experiences at the core.

Unlike most traditional engineering courses the PDD degree features group DBT projects in all years of the programme. The projects increase in complexity and challenge in a staged manner, with learning outcomes guided by Bloom's taxonomy of learning domains. The integrated course structure enables the immediate application of disciplinary knowledge, gained from other modules, as well as development of professional skills and attributes in the context of the DBT activity. This has a positive impact on student engagement and the embedding of these relevant skills, identified from a stakeholder survey, has also been shown to better prepare students for professional practice.

This paper will detail the methodology used in the development of the curriculum, refinements that have been made during the first five years of operation and discuss the resource and staffing issues raised in facilitating such a learning environment.

\section{Introduction}

The CDIO Initiative, aimed at reforming engineering education, was established in 2000 by the Massachusetts Institute of Technology and three Swedish universities; KTH - Royal Institute of Technology, Linköping University and Chalmers University of Technology. Queen's University Belfast (QUB) was the first UK University to join the initiative which now has more than 50 collaborating institutions from 25 countries worldwide. Working together and drawing on extensive stakeholder and alumni surveys, the group has produced a syllabus and a set of 12 standards which provide a comprehensive description of the level of knowledge, skills and attributes that graduates of engineering programmes should be expected to acquire. The requirements extend beyond the traditional discipline specific technical knowledge to include product and system building knowledge and skills, personal and professional skills and interpersonal skills. The CDIO approach does not imply that the technical content of a programme should be reduced, but rather that by teaching the discipline in the context of conceiving, designing, implementing and operating a product or system, opportunities to develop these additional skills and attributes are provided at the same time, thus increasing the scope of what can be learned. Further, the CDIO approach demands that programmes are consciously designed to produce the desired learning outcomes derived from the characteristics and abilities identified as requirements by the stakeholders. The Product Design and Development (PDD) degree programme at Queen's University Belfast was the first entirely new degree programme to adopt the CDIO methodology as the basis for its curriculum, accepting its first students in 2004. To formally define the methodology and to serve as a guide to how CDIO might be applied to enhance existing programmes or develop new courses a textbook has been published by the CDIO collaborators. (Crawley et al, 2007) 


\section{Background to the PDD Degrees}

One of the first activities carried out by the School of Mechanical and Aerospace Engineering (SMAE) at QUB on joining the CDIO initiative in 2003 was to undertake a stakeholder survey of employers, alumni, staff and students. Primarily this set out to identify the level of proficiency required to be professionally competent engineers in the disciplines already being taught by the School, namely Mechanical, Manufacturing and Aerospace Engineering. 800 hardcopy questionnaires were distributed of which just over 200 were returned. Respondents were asked to rate the level of proficiency required and the importance of items on the CDIO syllabus on a scale of 1 to 5 , with 5 being the highest level of importance. The same exercise was also carried out by other CDIO collaborators which additionally allowed for comparison between countries and disciplines to be made. A sample of the survey results covering sections 2 to 4 of the CDIO syllabus is shown in Figure 1.

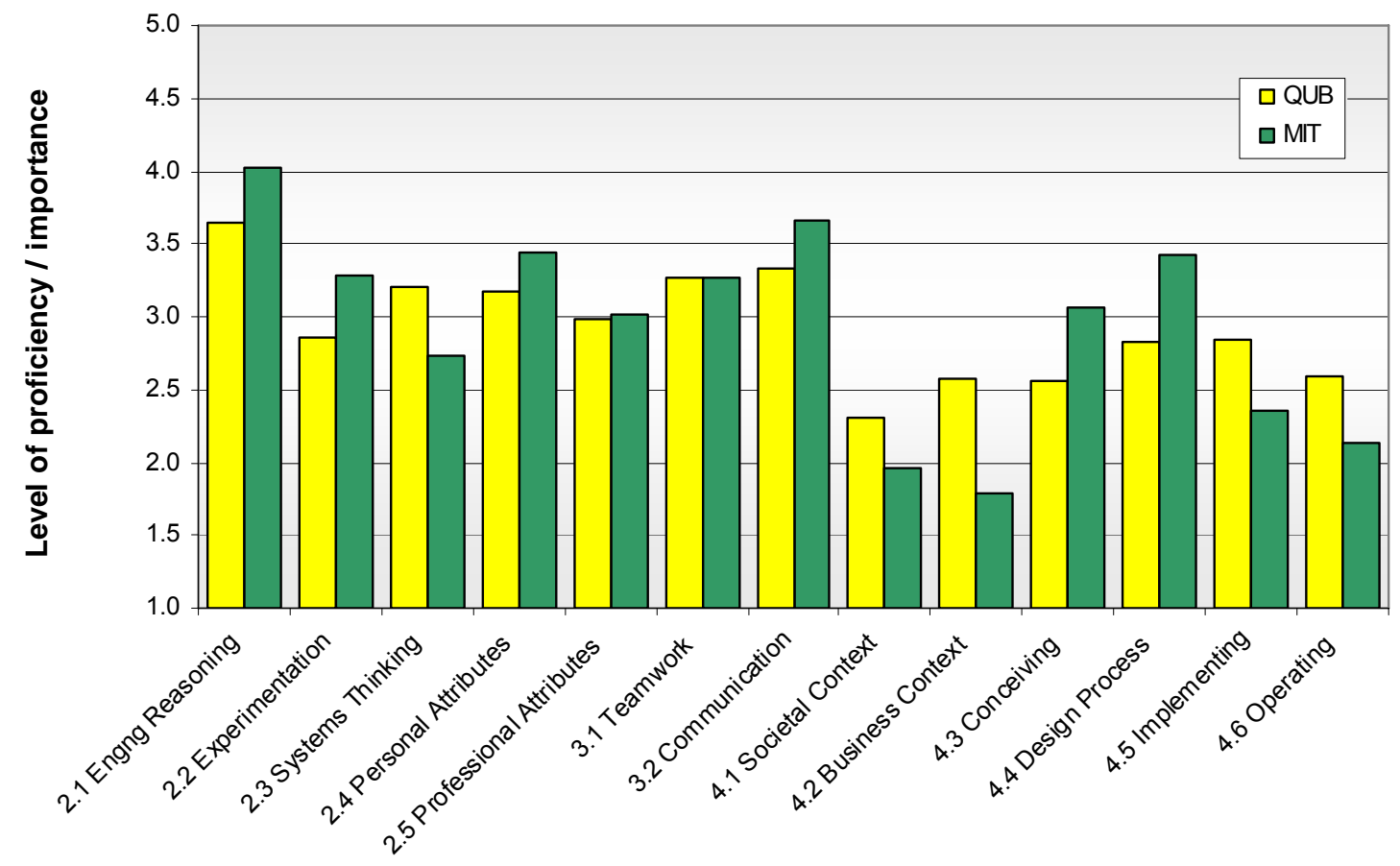

Figure 1: Sample of Stakeholder Survey Results (QUB \& MIT)

The QUB questionnaire also asked questions regarding the balance between different areas of the curriculum. Alumni suggested that less time should be devoted to engineering science, mathematics and traditional laboratory experiments and considerably more time to design-build projects and the development of professional skills. This view was not shared among the staff who generally considered that an increased percentage of non engineering science content would effectively "dumb down" the programmes and diminish their quality and value. The challenge presented by the survey was to plan and deliver an integrated curriculum that could meet the expectations of industry in terms of professional skills and attributes without sacrificing the scientific and mathematical rigor of the traditional engineering degree; in essence exactly what a CDIO structured degree aims to achieve.

Concurrent to the evaluation of existing programmes, with an intention of restructuring them to be more CDIO compliant, it had been noted that there were a diminishing number of A-Level students sitting Mathematics and Physics exams. These subjects were among the requirements for admission to all programmes in the School with mathematics being an essential requirement. The trend was similar in relation to Mathematics across the UK but there had been a significantly greater downward trend in the numbers doing Physics in N.Ireland. Since approximately $95 \%$ of students admitted to SMAE are local (i.e. from N.Ireland) this reduction in the pool of potential students was an acute problem which had started to have an impact both on the number and standard of students entering the School. Figures $2 \& 3$ show N.Ireland and UK trends for A-Levels over the last 9 years in subjects currently considered appropriate as part of the admissions process to SMAE at QUB. 


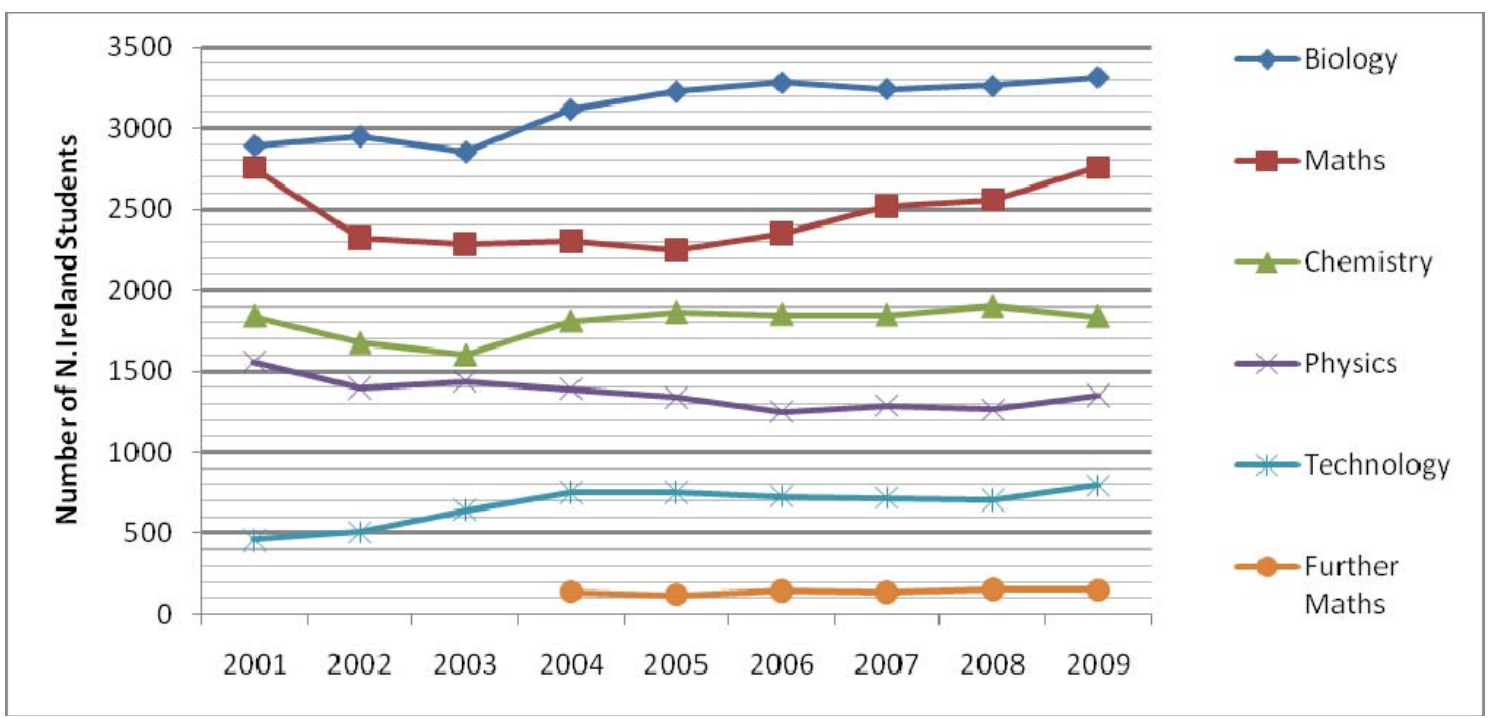

Figure 2: N.Ireland A-Level Trends 2001-2009 (Source: Joint Council for Qualifications)

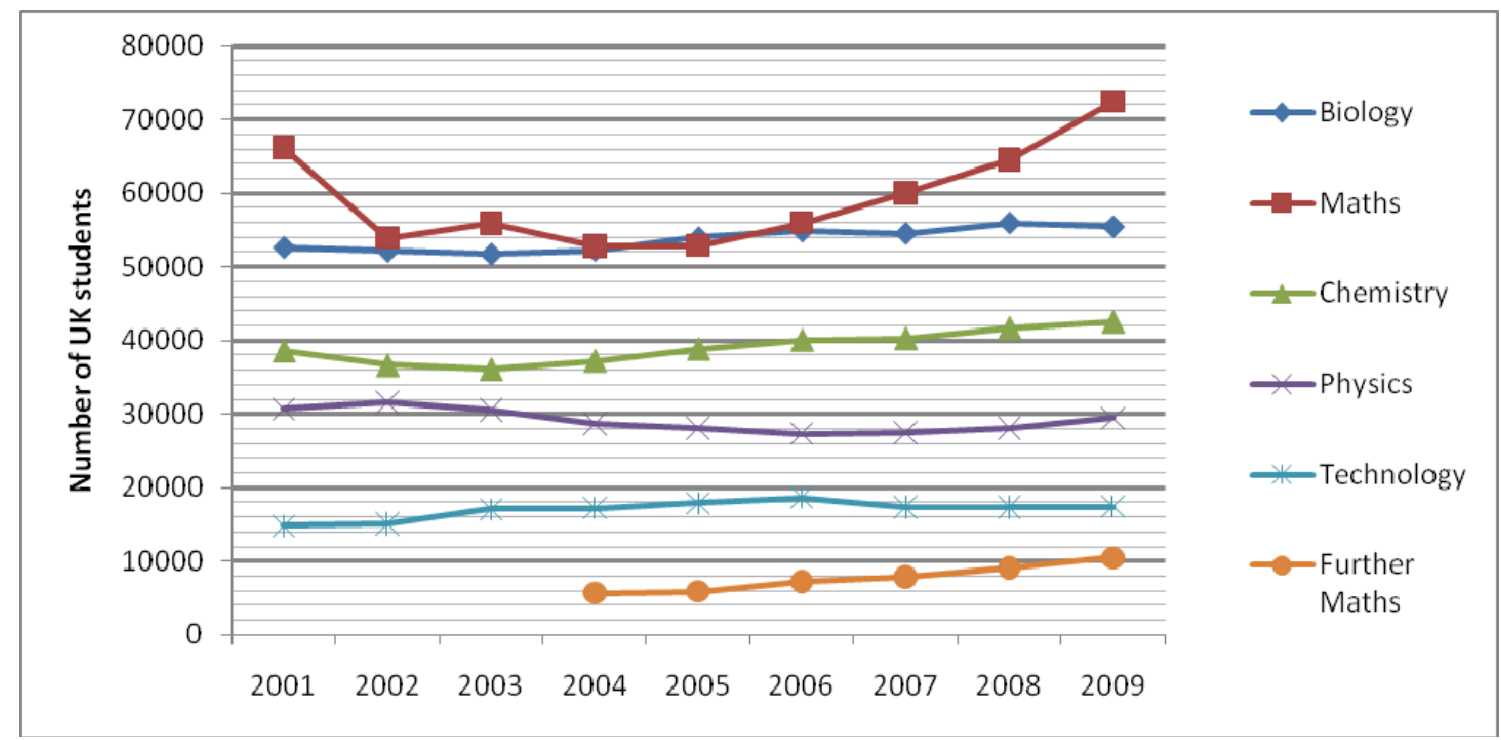

Figure 3: UK A-Level Trends 2001-2009 (Source: Joint Council for Qualifications)

At the same time, Design \& Technology (D\&T) A-Level was growing rapidly in N.Ireland and was seen as having potential to be a substitute on the School's admission criteria, in place of physics or another science subject. QUB staff had also been involved with a UK Government funded "CADCAM in Schools" initiative with local D\&T teachers and had developed an understanding of the syllabus of this growing subject. It was decided that the new PDD degree would have a broader set of acceptable ALevel subjects than the other engineering programmes and that D\&T would be included. It was intended that not only would this mitigate against any potential drop in student numbers but that the profile of the intake would be more varied. It was hoped that this variety among the cohorts could be used to create project groups which more closely resemble the mixed discipline teams found in industry. It should be noted that in the years since 2004 the growth of D\&T in N.Ireland has stopped and the downward trends in physics and mathematics have been reversed.

While a decision was made to improve the existing programmes using the CDIO methodology by means of a rolling programme of managed change, it was also decided that there existed an opportunity to take a more radical approach with the new PDD degree. Starting with a blank sheet of paper the curriculum was designed to fully address all the CDIO standards. 


\section{Curriculum Design}

The first $3 \mathrm{CDIO}$ standards are particularly relevant to programme development.

CDIO Standard 1 - CDIO as Context

Adoption of the principle that product and system lifecycle development and deployment Conceiving, Designing, Implementing, and Operating - are the context for engineering education.

CDIO Standard 2 - CDIO Syllabus Outcomes

Specific, detailed learning outcomes for personal, interpersonal, and product and system building skills, consistent with program goals and validated by programme stakeholders

CDIO Standard 3 - Integrated Curriculum

This standard demands that the curriculum is designed with mutually supporting disciplinary subjects and with an explicit plan to integrate personal, interpersonal, and product and system building skills.

The design brief for the PDD degree was that it would produce graduates who were professionally competent in the process of new product development. This requirement had been identified by a number of strategy documents produced by Government agencies such as InvestNI and was also cited by companies who responded to the QUB stakeholder survey. In addition, reports such as the "Cox Review of Creativity in Business" (commissioned by the UK Chancellor of the Exchequer) suggested that there was an untapped pool of creative talent that could reinvigorate the UK technology sector.

As with the development of any product, having identified an unfulfilled customer need, the next phase is to scope the project to establish viability. It was by no means certain that the School had within its resources the ability to deliver a programme that could meet all of the CDIO standards. It was necessary therefore to first establish a logical sequence of progression through the different years of the degree. As a starting point the premise was that subsequent years would cover more of the 4 CDIO phases (Conceive-Design-Implement-Operate) of new product development. Year 1 would focus on the identification of customer needs and the conversion of these into design concepts ( $C$ and some D). Year 2 would add more detailed design and manufacturing considerations (C, D and some I) and year 3 would then also include business planning and production management (C,D,I and some O). In this way students would build on previous knowledge in manageable steps until by the end of year 3 they were experienced in all phases of product development as illustrated in Table 1. Bachelor of Engineering (BEng) students study a 3 year programme while Master of Engineering (MEng) students study for 4 years.

Table 1: QUB PDD degree overview

\begin{tabular}{|l|l|l|}
\hline & Focus of content & CDIO phases \\
\hline Year $\mathbf{1}$ & $\begin{array}{l}\text { Creative skills and the discipline of design. } \\
\text { Introductory course. }\end{array}$ & C and some D \\
\hline Year $\mathbf{2}$ & $\begin{array}{l}\text { Focus on design and manufacturing linked to } \\
\text { group prototyping projects. }\end{array}$ & C, D and some I \\
\hline Year $\mathbf{3}$ & $\begin{array}{l}\text { Focus on Business and production management. } \\
\text { Major Group Project. }\end{array}$ & C,D, I and some O \\
\hline Year $\mathbf{4}$ & $\begin{array}{l}\text { Engineering design and analysis. } \\
\text { Work placement / study abroad. }\end{array}$ & C, D, I, O \\
\hline
\end{tabular}

The design brief was then expanded from this into a programme specification which includes a comprehensive list of learning outcomes covering knowledge and understanding, subject specific skills, cognitive and transferable skills.

The PDD degree differs from the structure of a traditional engineering degree which can be characterised as having 4 stages. In stage 1 mathematics and science is taught, in stage 2 
engineering fundamentals, stage 3 has specialised and elective courses and stage 4 has summative experiences. Fundamentally this type of course is structured around the content and not the context with the curriculum designed to teach disciplinary knowledge in a sequential manner where topics build upon each other. The development of student skills and attributes may not have been planned at all, and any skills acquired happen more by accident than by planning. This may be due to the necessity to operate a modularised and semester based system. Often modules have no relationship to or interaction with one another. In the case of professional skills these are often "bolted on" and delivered by staff from outside the School without context and by non engineers. Students may find themselves in large classes along with others from very different disciplines and the content is often generalised and non specific with no relevant examples which the students can easily relate to. The authors recognise these characteristics well from their own undergraduate experiences in the 1980s and 90s.

CDIO standard 5 requires an introductory course that incorporates design-build experiences followed by at least one further design-build exercise of a more advanced and demanding nature. The development of a new degree offered an opportunity for a radical approach and subsequently a decision was made to develop a curriculum that went beyond this minimum requirement to include a project based course in every year of the programme that would act as the core of an integrated curriculum. Around this core are modules which primarily develop either technical knowledge or professional skills and attributes as illustrated in Figure 4. The opportunity for immediate application of the skills and knowledge comes through appropriate selection of the themes for the design - build experiences in the core modules.

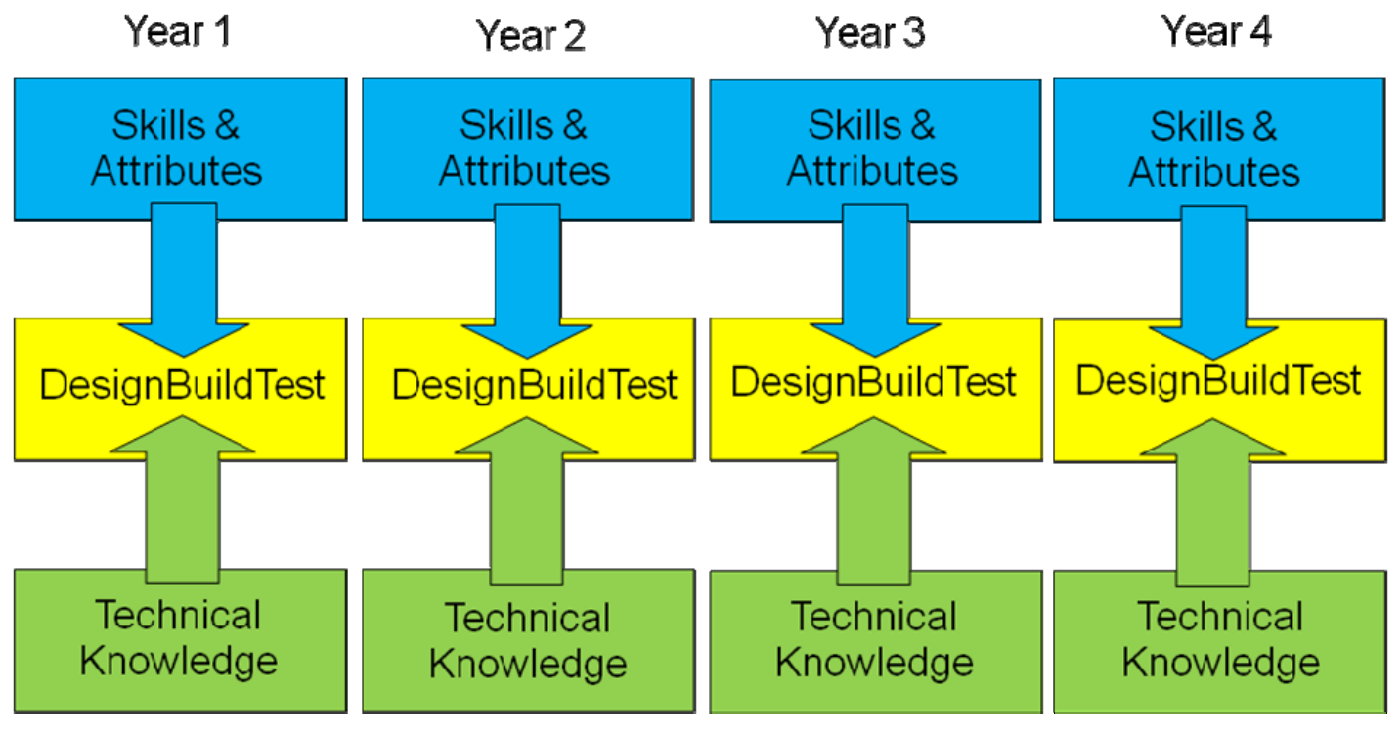

Figure 4: Fundamental structure of PDD degree

As a generic model the principle is easily understood. What was required however was to develop a detailed curriculum with the appropriate balance of core modules engineering science and courses focused on skills development. It is also important to select themes for projects in each year which enable the application of the technical knowledge being acquired during the same time period.

Figure 5 shows the structure of year 1 of the PDD degree with 1.5 core DBT modules "Introduction to Product Design 1" and "Design Project 1" running up the centre of the schematic. Above this are 2.5 modules worth of mostly skills development and below are 2.0 modules of predominantly technical knowledge. It should be noted however that modules are not all one type of learning and indeed through the application of active and interactive learning techniques to all modules, as a result of the work of a Centre of Excellence in Teaching and Learning (CETL) within the School, an increasing amount of skills such as oral presentation are now developed in what had previously been traditional "chalk and talk" engineering science subjects.

The arrows in Figure 5 indicate where there is an opportunity to apply the skills and knowledge to the DBT projects at the core. The detail of how this is done needs to be negotiated between the module co-ordinators under the guidance of the Programme Director who has an overall view of the 
programme. Additionally the level of all learning outcomes expected in each year need to be considered to ensure that a developmental path is achieved throughout the entire programme of study. To assist in this, Bloom's taxonomy of learning domains is used (Bloom, 1956). The taxonomy categorises learning behaviour into 6 levels and provides descriptors and key words to assist in the design and assessment of the learning process. The different levels can be used to indicate the expected performance level of the student by carefully choosing words from the taxonomy when writing the learning outcomes for each module. A more detailed description of how Bloom's taxonomy has been applied to the core DBT modules can be found in the authors' paper presented at the $5^{\text {th }}$ International CDIO conference (Hermon et al, 2009).

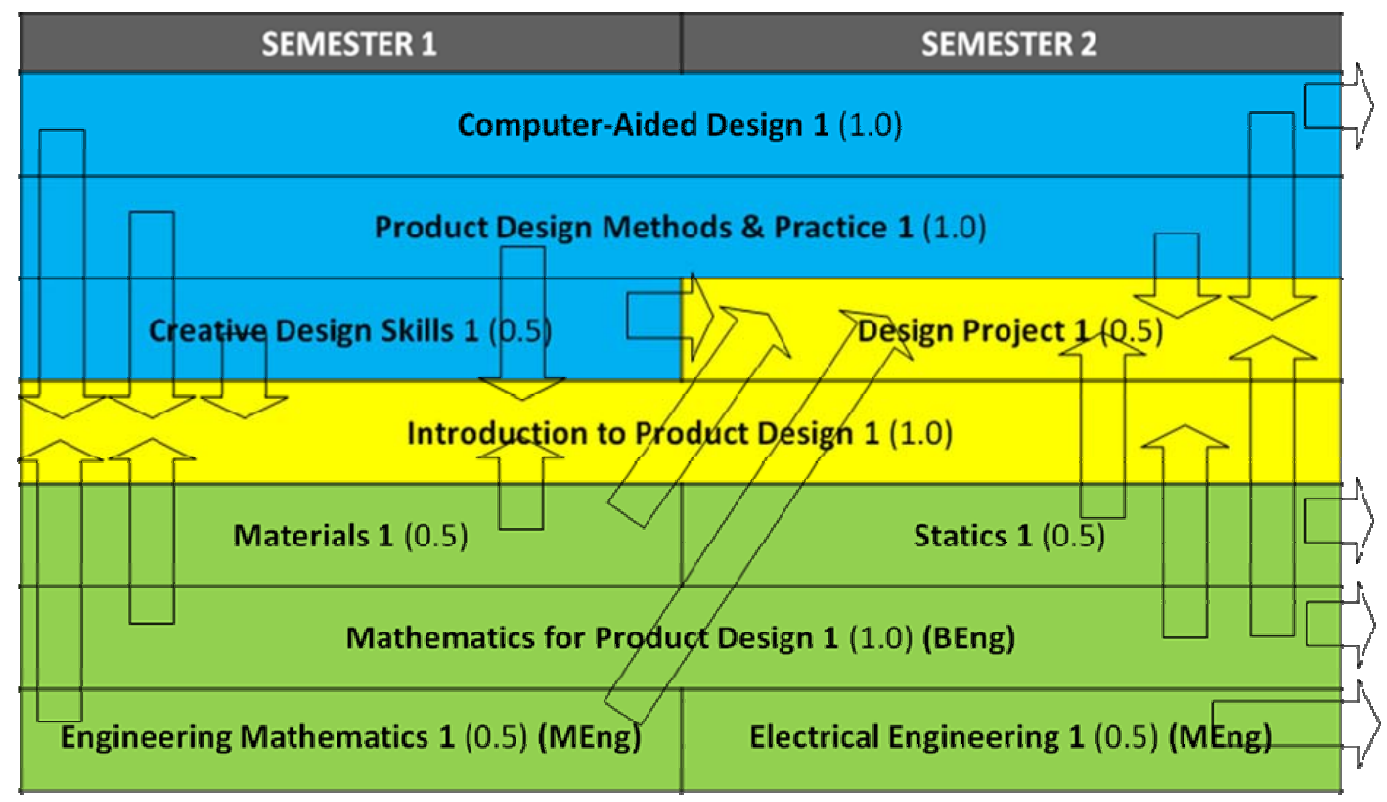

Figure 5: Integrated curriculum - Year 1 PDD

A set of specific learning outcomes for undergraduate programmes is defined in the UK-SPEC published by the Engineering Council UK. The Institution of Mechanical Engineers (IMechE) also uses the same set of outcomes when examining a course for accreditation. There are currently 27 learning outcomes specified across 5 categories which cover both disciplinary knowledge and professional skills and attributes. Part of the IMechE accreditation process focuses on identifying where these learning outcomes are delivered in the modules of a degree program. A matrix is produced for all modules over all years of the degree to help identify any gaps or imbalances that occur. Since a similar approach had been used in designing the new PDD degree to ensure that the relevant learning outcomes of both the CDIO syllabus and UK-SPEC were met, these were transposed with relative ease to the IMechE matrix. The BEng and MEng PDD degrees were submitted for the first time and subsequently accredited by the IMechE in 2009.

\section{Refinements}

During the first year of the PDD degree the slot in the timetable now filled by the "Introduction to Product Design" module was taken by a course which concentrated on dissection and analysis of products. A parallel exercise to develop introductory courses for the Mechanical and Aerospace Engineering degrees, as part of a structured change management process (McCartan et al, 2008) to meet the requirement of CDIO standard 4, highlighted that, while using a commendable amount of active and interactive learning, the dissection class was missing opportunities to act as more of a core element in an integrated curriculum. The assessment regime was seen as too narrow and the lack of redesign of analysed products meant there was little chance to apply technical knowledge. By reusing some of the dissection artefacts as a starting point for more design focussed projects, opportunities to 
apply presentation skills, to produce concept sketches and prototype models have now been created. Group meetings to discuss and evaluate concepts introduce more interpersonal and team working skills and the breadth of deliverables required necessitates time management and efficient use of the team's resources.

In order to mimic professional practice, DBT projects are carried out in teams in all years of the degree. The rationale here is that by changing the members of the groups between projects the students need to adapt to different team dynamics and hence develop better interpersonal and team working skills through this repeated application. The increased number of projects also facilitates deeper learning and gives more opportunities for feedback. It was noted however that by year 4 , when a 1.0 module major individual design project is part of the programme, that several students had evidently taken a strategic approach in the preceding years choosing to concentrate on what they were best at so that the team optimised the use of its existing skills. While this may well be accepted as best practice in industry, where the objective is to get the best from the finite resources available, it can serve to reinforce an avoidance tendency in an educational context rather than encourage broader personal development. This characteristic was particularly evident in the area of CAD skills where a "CAD jockey" would often volunteer for this part of the project to the detriment of their personal development in other areas. Consequently other members of the group can also easily become excluded from the CAD activities and subsequently miss the opportunity to develop what is a weaker area of their own skill set. This has been tackled in 2 ways. An additional half module of individually assessed CAD has been introduced at the start of year 2 with tasks which develop skills that can be directly applied to the year 2 group projects in another module. Further, the assessment of the group projects and associated learning outcomes have been modified to include reward for peer mentoring, management and leadership skills. This is assessed by increased supervisor observation including the use of an online project blog and by having sections of the peer assessment spreadsheet refer explicitly to these management and leadership skills. In general the learning outcomes for these projects include an increased percentage of the marks for process rather than product. How the students operate as a project team is assessed as much as the final report and prototype. To be effective this has been backed up by increased interim feedback and monitoring. This, however, has proven to be time consuming and resource intensive. The current focus of development in this area is on achieving the same educational environment more efficiently.

Workspace resources are also an issue which has arisen from the transition of the degree programmes in the School to a CDIO model. Traditional lecture theatres with fixed rows of seating are not suitable for many active and interactive learning activities. The Ashby tower block, which is home to SMAE, is currently undergoing a major refurbishment, due to be completed in September 2010. The requirement for teaching spaces compatible with this new method of teaching has been the key driver in developing the specification of this facility. More small rooms to hold project meetings are required. Additional facilities and material resources for prototyping are also included in the refurbishment plans. Larger team working rooms with freestanding furniture will facilitate a variety of uses. Studio spaces and teaching areas with moving walls will also provide further flexibility.

\section{Evaluation}

Built into year 4 of the MEng PDD programme is a 12 week work placement which has enabled an evaluation of the preparedness for professional practice. Employers who act as hosts for these placements are asked to comment on the suitability of the students to the role carried out. The students are required to produce a reflective report of this experience as part of their assessment. This includes a discussion of knowledge and skills from their degree course which have been applied during the placement. In this way a mechanism for continual feedback with employer input has been established as part of the annual programme review (Quality Assurance) process.

During 2009 the School underwent two separate audits of teaching quality. IMechE reassess their accreditation of degree programmes every 5 years, including a thorough examination of the learning outcomes against UK-SPEC. In 2004 the School had just begun to implement CDIO principles to its courses. By 2009 these principles formed the basis of the submission regarding the PDD degree which was being assessed for the first time. In their report (section 3.0 Philosophy, Aims and Objectives) the IMechE visiting team commented that:

"The CDIO process is a commendable benefit which has 36 other Institutions worldwide joined up, all operating with real world products, processes and systems. The CDIO is quite a shift in teaching style and the School are fully engaged with staff able to attend the CDIO yearly 
conferences to give them ownership and full understanding of the best practices in the UK. The documentation showed some previous poor attendance and the CDIO does reflect enthusiasm and an increase in attendance with positive feedback as it encourages team working and a competitive edge."

"The School uses 'Bloom's taxonomy' to determine the level of learning in each year; i.e. remember, understand, apply, analyse, evaluate and create. Mapping these against the different stages of the programme to test the appropriate learning outcomes, this is in conjunction with the mapping against UK-SPEC."

Queen's University Belfast also introduced a new internal audit system in 2008, the Educational Enhancement Process (EEP), which focuses on how each School is enhancing its educational provision and the student experience. The EEP panel includes members of academic staff from other Schools in the university, 2 external academics of the same discipline from different UK universities and students from with the School. SMAE was examined under this process in 2009. Section 2 of the panel's report deals specifically with enhancing the quality of education provision and reported that:

"Curriculum development is guided by the School's involvement in CDIO and conducted in a top-down manner. Starting from a generalised engineering syllabus, developed by the CDIO consortium, a programme specific syllabus is developed. This syllabus is then evaluated by the stakeholders - students, staff, alumni and industry - to assess its relevance and also to define the required proficiency levels for each of the syllabus items. The results of this exercise, along with subject accreditation criteria enable the development of programme learning outcomes, and then modules and module learning outcomes.

A key driver for curriculum development is the desire to better prepare students for professional practice. The Panel were impressed at through the School's general involvement in CDIO and at the way in which this approach compliments the University's published policy on employability skills."

"The Panel also gave its full support to recent developments which were considered to have enhanced the curriculum, in particular the development of the Product Design and Development programmes based on the CDIO methodologies"

\section{Conclusions}

- The CDIO syllabus can be used as an effective basis for curriculum development that is compatible with the requirements of UK-SPEC.

- The PPD curriculum developed at QUB has been endorsed by two independent audits of teaching quality carried out in 2009.

- Ongoing evaluation of student attainment in relation to the stated learning outcomes of the programme has resulted in modifications to the original course structure.

- A change to a CDIO based teaching methodology requires capital investment to develop appropriate teaching workspaces.

\section{References}

Bloom, B.S., (1956) Taxonomy of Educational Objectives: Handbook 1, The Cognitive Domain. New York: David McKay Co. Inc.

Crawley, E.F., Malmqvist, J., Östlund, S., Brodeur, D.R., (2007) Rethinking Engineering Education The CDIO Approach. New York: Springer

Hermon, J.P., McCartan, C.D., Cunningham, G., (2009) Enhancing the Educational Development of Individuals in Group Projects. Proceedings of the 5th International CDIO Conference, Singapore Polytechnic, Singapore, June 7 - 10, 2009

McCartan, C.D., Cunningham, G., Buchanan, F.J., McAfee, M., (2008) Application of a generic curriculum change management process to motivate and excite students. Engineering Education: Journal of the Higher Education Academy Engineering Subject Centre: volume 3 issue 2 (37-44) 


\section{Acknowledgements}

The authors wish to acknowledge the outstanding contribution made by the late Professor Perry J. Armstrong, former Director of Education in the School of Mechanical and Aerospace Engineering. Perry took the lead in the School's involvement in the CDIO Initiative, which has made a significant contribution to the enhancement of our programmes. It was also Perry's foresight that recognised the need for the PDD degree and his hard work and support that contributed to its success.

\section{Copyright statement}

Copyright $\odot 2009$ JP Hermon, CD McCartan, G Cunningham: The authors assign to the EE2010 organisers and educational non-profit institutions a non-exclusive licence to use this document for personal use and in courses of instruction provided that the article is used in full and this copyright statement is reproduced. The authors also grant a non-exclusive licence to the Engineering Subject Centre to publish this document in full on the World Wide Web (prime sites and mirrors) on flash memory drive and in printed form within the EE2010 conference proceedings. Any other usage is prohibited without the express permission of the authors. 